Pensares em Revista, ISSN 2317-2215

\title{
RELATO DE EXPERIÊNCIA: SEQUÊNCIA BÁSICA DE LEITURA PARA AMPLIAR A RELAÇÃO DO TEXTO COM O LEITOR
}

\author{
João Carlos BIELLA \\ (Universidade Federal de Uberlândia) \\ jocabiella@bol.com.br \\ Conceição Maria Alves De Araújo GUISARDI \\ (Universidade Federal de Uberlândia) \\ ceicaguisardi@hotmail.com \\ Francisca Borges BARBOSA \\ (Universidade Federal de Uberlândia) \\ francisca2 @hotmail.com \\ Caroline Costa SILVA \\ (Universidade Federal de Uberlândia) \\ carol257@hotmail.com
}

Resumo: $O$ presente relato de experiência tem como objetivos encorajar os alunos a experimentar leituras sensíveis, ampliar a receptividade dos alunosleitores, contribuir para que os alunos vivenciem as sensações e emoções que os abrigam durante a leitura, conduzir os alunos à lógica associativa (intertextualidade e interleitura), desenvolver no aluno as habilidades necessárias à competência leitora. Sabendo da necessidade de criar oportunidades para que nossos alunos possam desenvolver a imaginação criadora, a atenção, compreender as relações espaciais, a expressão e, sabendo, ainda, que imaginar e fantasiar são habilidades que devem ser alimentadas na infância e na adolescência, motivamo-nos a planejar uma sequência didática básica (Cosson, 2012) de leitura a fim de aproximar o leitor do texto. Nosso estudo está pautado em Cosson (2012), mormente, que afirma que é tarefa do professor partir daquilo que o aluno já conhece para aquilo que ele desconhece, levando o aluno ao crescimento como leitor. Escolhemos as obras Alice no País das Maravilhas e $A$ Bolsa amarela, para trabalharmos o texto literário. Exploramos o conteúdo das obras e sua aproximação com a realidade de vida do público alvo, alunos do sétimo ano do Ensino Fundamental, no que se refere aos conflitos e indagações dos sujeitos dessa faixa etária, na busca de identidade. Pretendemos, ainda, que eles relacionem situações das duas obras com sua própria realidade, o que os ajudará a lidar melhor com os conflitos da vida real.

Palavras-chave: Texto literário. Sequência Básica. Leitor. Texto. 


\title{
CASE STUDY: USING A DIDACTIC SEQUENCE ON READING TO ENHANCE THE INTERACTION BETWEEN THE READER AND THE TEXT
}

\begin{abstract}
This article aims to encourage students to try sensitive readings, to broaden their receptivity to reading, to help them experience the sensations and emotions that are produced while reading, to develop with them an associative logic (intertextuality and reading) as well as the necessary skills to help them become competent readers. Being aware of the need to create opportunities for our students to develop their creative imagination, attention, understanding of spatial relations, as well as their expression and also being aware that imagination and fantasy are skills that must be fed in childhood and adolescence, we can say that all these issues motivated us to plan a basic didactic sequence (Cosson, 2012) on reading in order to approximate these readers to the text. Our study is based on Cosson (2012), mainly, since this author advocates that it is the teacher's duty to start the teaching process by identifying and using what the student already knows, leading him/her to grow as a reader. We chose the books Alice in Wonderland and the Yellow bag to work the literary text in order to explore the contents of these books and their approach to the reality of life of the target audience, students of the 7th (seventh) year of elementary school, with regard to their conflicts and quests, to their search of their identities. We also aim at helping them link the situations encountered in the books with their own reality, what, we hope, will help them to better cope with the conflicts of real life.
\end{abstract}

Keywords: Literary text. Basic didactic sequence. Reader. Text. 
A única forma de chegar ao impossível é acreditar que é possível. (Alice no País das Maravilhas, de Lewis Carroll)

É importante que o contato com a literatura aconteça desde a infância, por meio dos contos de fadas, fábulas, parlendas, trava-línguas e outras infinitas possibilidades de acesso ao mundo da leitura, dentro de um contexto significativo.

Para Candido (1995), a literatura representa todas as citações de toque poético, ficcional ou dramático em todos os níveis de uma sociedade, em todos os tipos de cultura. $O$ autor reafirma que os tipos de cultura envolvem desde o que chamamos de folclore, lenda, chiste, até as formas mais complexas da produção escrita das grandes civilizações.

Enfatizamos, então, a importância dos textos literários que são responsáveis por entreter, que apresentam o belo, a ficção, a arte, enfim, tem uma função estética. E não podemos esquecer que, em tempos atuais, muito tem se discutido sobre a literatura, que constitui mais do que um conjunto de textos com finalidades estéticas, configurando-se como um ato de comunicação.

Cosson (2012) defende que o processo de letramento que se faz via textos literários compreende não apenas uma dimensão diferenciada do uso social da escrita, mas também, e, sobretudo, uma forma de assegurar seu efetivo domínio.

A necessidade de trabalhar com o texto literário, fazendo com que ele se torne um meio de aproximação do leitor com o texto e evidenciando que a literatura não deve ser vista como pretexto para ensino de gramática e nem como apêndice da língua, foi a motivação para escolhermos obras que os alunos apreciam, pois assim teriam prazer em desenvolver as atividades propostas. Essa necessidade de aproximar o leitor do texto, reconhecendo-o como sujeito leitor e criativo, vem sendo bastante destacada por vários pesquisadores e teóricos, tais como Cosson, Rouxel, Iser, dentre outras referências de estudo em leituras literárias e letramento literário.

Escolhemos, então, as obras Alice no País das Maravilhas ${ }^{1}$ (de Lewis Carroll) e a Bolsa Amarela ${ }^{2}$ (de Lygia Bojunga) para trabalharmos o texto literário

\footnotetext{
${ }^{1}$ Alice no país das maravilhas é a narrativa do sonho de uma garotinha. Como em um jogo. A garotinha precisa entender e resolver o jogo, antes que sua irmã a acorde e a traga de volta ao mundo real e normal. Alice é uma obra que permite várias interpretações. Uma delas é a de que as mudanças, conflitos e aprendizados da adolescência podem estar representados na obra. Alice entra na aventura sem pensar em nada, de repente, como se entra na adolescência. A questão do tamanho nos lembra que a adolescência está presente em todos os episódios da história: "Alice está sempre crescendo e diminuindo dependendo da
} 
com toda a sua carga de interação, arte e possibilidade de criação e comunicação. Elaboramos então, uma sequência básica, baseadas nas idéias de Cosson (2012) e essa proposta foi aplicada em uma escola pública do Distrito Federal para alunos do sétimo ${ }^{\circ}$ ano.

Na obra Alice no País das Maravilhas, presenciamos toda uma riqueza de detalhes, de estética, que encanta tanto o público infantil, quanto o juvenil. Nesse livro, que retrata tão bem o imaginário e o maravilhoso, notamos todos os conflitos da adolescência. Por sua riqueza, ele é um dos livros mais editados da literatura moderna e, é também, o grande responsável por influenciar vários escritores, dentre eles, Maria Clara Machado e Guimarães Rosa.

De igual maneira, a obra $A$ Bolsa Amarela nos transporta para um mundo imaginário e nos faz perceber e compreender melhor os conflitos e aprendizados que o adolescente vivencia na transição de vida infantil para vida jovem-adulta.

Enquanto Alice, protagonista da obra Alice no País das Maravilhas, cresce e diminui dentro da fábula, em função da situação, Raquel, a protagonista do romance A Bolsa Amarela, questiona o mundo dos adultos e encontra respostas para seus próprios questionamentos.

A esperteza das duas meninas, visível no enredo das obras, é bem parecida com a dos nossos alunos adolescentes. Enquanto a menina Raquel é uma "inventadeira", Alice nos transporta para um mundo imaginário pronto. Temos como o maravilhoso das duas histórias, o coelho, na história de Alice, e a bolsa amarela, na história de Raquel, além de várias outras personagens que participam de um mundo fantástico, onde o imaginário e o real se misturam.

Nesse contexto, destacamos, como defende Rouxel (2012), a necessidade de buscar um leitor real. Consideramos, também, que a literatura, que tem o

\footnotetext{
situação e isso certas vezes é conveniente ou não para ela. (NEPOMUCENO, s.d, p.1) < Disponível em<http://www.psicologiananet.com.br/analise-psicologica-e-interpretativa-do-romance-alice-no-pais-dasmaravilhas/1858/>

${ }^{2}$ Raquel, personagem central de A bolsa amarela, sofre ao se defrontar com as dificuldades impostas pelo esquema dominador do mundo dos adultos e busca respostas para os seus questionamentos. Ao se ler a história contada por Raquel, percebe-se que a linguagem utilizada é própria do mundo infantil; passa-se a conhecê-la por seu vocabulário, pelo registro informal e pela criação de palavras, fato comum nessa fase da vida humana. Dessa forma, Lygia Bojunga consegue dar voz à protagonista de Bolsa amarela: a linguagem coloquial usada pela menina a revela. (NAVARRO, 2008, p.1) Disponível em: $<$ http://www.psicologiananet.com.br/analise-psicologica-e-interpretativa-do-romance-alice-no-pais-dasmaravilhas/1858/>
} 
imaginário e a ficcionalização como elementos constituintes de sua identidade, transforma a realidade em linguagem.

Ler e escrever são ações complementares. Acreditamos que leitores proficientes são escritores proficientes. Compreendemos, também, que o trabalho com literatura na escola deve levar em conta, além dos princípios já expostos nesse estudo, a diversidade social, os diferentes gêneros orais, escritos e multimodais ${ }^{3}$.

De acordo com Rouxel (2007) é necessário encorajar abordagens sensíveis de obras, a fim de despertar para a recepção dos alunos ou daquilo que eles aceitarão manifestar de sua experiência estética.

Acreditamos que, ao desenvolvermos esse trabalho em sala de aula, proporcionamos, aos alunos, experiências efetivas de leitura; e experiências de sucesso com a literatura em sala de aula são aquelas em que o aluno interage com os diversos textos trabalhados de forma que possibilite o entendimento do mundo em que vivem, para que construam, aos poucos, seu próprio conhecimento.

Apesar de muitas mudanças no ensino de Língua Portuguesa já terem ocorrido na educação nos últimos anos e de todo avanço tecnológico, ainda temos um ensino de literatura que não leva em conta as experiências de leitura dos alunos. O livro didático não oferece o contato estético de leitura. Porém, sabemos que, ao falarmos de um estudo significativo do texto literário envolve a reflexão sobre qual tipo de escola queremos para a literatura, cabe também uma reflexão acerca não só do livro didático, mas, do que os Parâmetros Curriculares Nacionais, PCN, nos trazem, das Tecnologias da Informação e da Comunicação, TICs, da grande instância biblioteca, enfim, pensarmos no espaço escolar como grande agência de letramento.

Cosson (2012, p.20) ressalta que "no ensino fundamental, a literatura tem um sentido tão extenso que engloba qualquer texto escrito que apresente parentesco com ficção ou poesia. O limite, na verdade, não é dado por esse parentesco, mas sim pela temática e pela linguagem".

Segundo esse autor, a literatura no ensino médio limita-se à literatura brasileira, ou melhor, à história da literatura brasileira, usualmente na sua forma

\footnotetext{
${ }^{3}$ Gêneros compostos por diferentes modos semióticos, tais como sons, letras, cores, imagens.
} 
mais indigente, quase como apenas uma cronologia literária, em uma sucessão dicotômica entre estilos de época, cânone, dados biográficos dos autores. Ele diz também que isso tudo vem acompanhado de formas fixas de textos e algum elemento de retórica, em uma perspectiva tradiconal.

Dessa forma, professor e aluno devem integrar-se com igual determinação no desenvolvimento do processo de ensino e de aprendizagem, conquistado a partir do uso de textos literários. Cosson (2012) diz que, "para muitos professores e estudiosos da área de Letras, a literatura só se mantém na escola por força da tradição e da inércia curricular, uma vez que a educação literária é um produto do século XIX que já não tem razão de ser no século XXI.” (p.20).

Iser apud Paulino (2005, p.5) destaca que:

O texto literário, além de acumular esteticamente muitos outros textos, revela e questiona também convenções, normas e valores sociais. Entretanto, assim definida essa função do texto literário, ainda seria necessário estabelecer esteticamente o papel de seu leitor.

Roxel (2012) evoca Compagnon (1998), na obra O demônio da Teoria; Literatura e senso comum (Le Démon de la théorie: littérature et sens commun), para defender que "a experiência de leitura, como toda experiência humana é sempre uma experiência dúbia, ambígua, estilhaçada”. (p.14). A autora ressalta ainda que essa experiência está entre "compreender e amar, entre a filologia e a alegoria, entre a liberdade e a restrição, entre a atenção ao outro e a preocupação consigo mesmo." (p.14).

No dizer de Rouxel (2012):

O interesse pelas experiências de leitura nos convida a pensar sobre a experiência primeira de leitura e o movimento de empatia que produz uma compreensão profunda do texto. Na perspectiva didática, isso nos conduz a reconsiderar a leitura literária em relação à leitura cotidiana, a entender essa relação como um continuum e não como uma ruptura, a observar, em situações de leitura diversificadas (interpostas, situadas, entre dois polos) [...] (p. 16).

Quanto mais cedo o estudante entrar em contato com o texto literário, melhor terá uma visão do universo que o cerca. Nesse momento, ocorre a possibilidade de ampliação do potencial criativo, além de ampliar o conhecimento.

Por assim ser, o trabalho com o texto literário se caracteriza não só como a possibilidade de aproximação de um instrumento de formação conceitual, mas 
também como possibilidades de aproximar o leitor do texto, desenvolvendo habilidades significativas de leitura. Portanto, trabalhar literatura presume inserir 0 aluno nesse formidável mundo experiencial da leitura. Partindo desse ponto, propomos trabalhar a sequência básica defendida por Cosson (2012) a qual detalharemos a seguir.

\section{1 - Metodologia: A sequência básica}

A metodologia desse trabalho não visa mostrar dados quantitativos, mas pautar-se em uma análise qualitativa dos resultados apresentados da proposta aplicada. Primeiramente, nos pautamos em uma pesquisa bibliográfica sobre as sequências básica e estendida defendidas por Cosson (2012).

Para Rampazzo (2002) qualquer espécie de pesquisa, em qualquer área, pressupõe e exige uma pesquisa bibliográfica prévia, quer para o levantamento da situação da questão, quer para a fundamentação teórica, ou ainda para justificar os limites e contribuições da própria pesquisa.

Após o estudo bibliográfico, partimos para a prática. Como já registramos, optamos pela sequência básica, aplicando a proposta para trinta alunos do ensino fundamental de uma escola pública, localizada na área geográfica Distrito Federal.

De acordo com Cosson (ibid) a sequência básica é formada por quatro passos: motivação, introdução, leitura e interpretação. Procuramos, ao aplicar a proposta, contemplar todos esses passos.

\section{2 - A motivação}

Nesse passo, intentamos trabalhar com uma produção oral, como forma de preparar o aluno para a boa receptividade de leitura das obras. Além disso, entregamos aos alunos bolsas amarelas confeccionadas pelas professoras e pedimos que guardassem. Depois eles iriam entender o porquê de ganharem uma bolsa amarela. 


\section{3 - Produção (oral)}

Planejamos nessa produção discutir com os alunos as seguintes questões: $\mathrm{Na}$ convivência com a sua família e no relacionamento com os adultos, como você agiria se os papéis fossem invertidos, ou seja, você na condição de pai/mãe adulto e o adulto na condição de filho? Você os trataria da mesma forma que é tratado? Será que a pessoa do sexo oposto é mais feliz que você? Será que uma viagem pelo mundo da fantasia muda a realidade?

Propusemos, então, a socialização das reflexões. A partir dessa produção oral, utilizada como motivação para aplicação da proposta, partimos para a apresentação das obras.

\section{4 - Introdução}

Obras: A Bolsa Amarela de Ligya Bojunga e Alice no País das Maravilhas de Lewis Carroll.
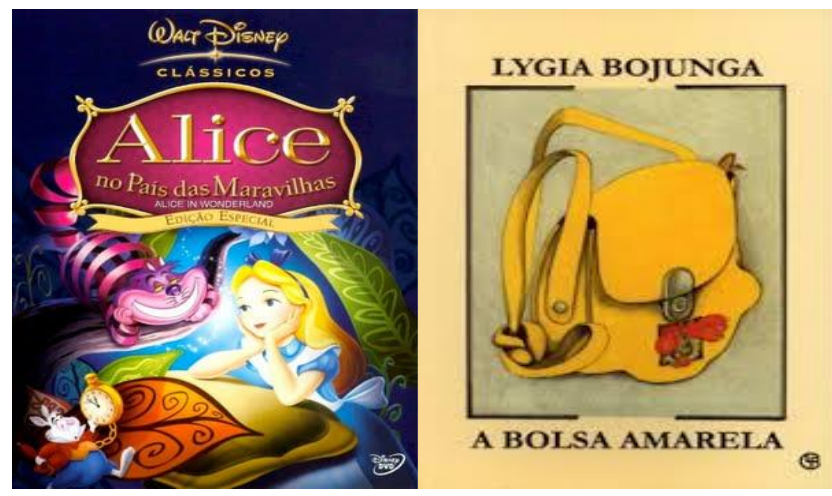

Fig. 1. As obras

Tempo previsto: 02 (dois) meses (levando em consideração o período destinado à leitura das duas obras). 


\section{Conhecendo as obras}

Apresentação da primeira obra: Bolsa Amarela

Cosson (2012) sugere que podemos levar o aluno à biblioteca para que retire os livros diretamente da estante. Ele afirma que "Independente da estratégia usada para introduzir a obra, o professor não pode deixar de apresentá-la fisicamente aos alunos." (p.60).

O primeiro livro a ser apresentado aos alunos foi "A Bolsa Amarela". Perguntamos o que mais chamava à atenção nesse livro. Comentamos, então, que a obra nos traz essa possibilidade de compreensão do que um menino e/ou menina sente na convivência com os adultos, principalmente, na convivência com a família e que muito se aprende também sobre a imaginação infantil. Comentamos, brevemente, sobre Raquel, a protagonista do livro, com o objetivo de instigar os alunos a imaginarem por que a autora deu esse nome para o livro.

\section{Apresentação da segunda obra: Alice no País das Maravilhas}

Para apresentação da segunda obra, discutimos, brevemente, sobre o mundo da fantasia e as suas criaturas fantásticas e sobre a troca do mundo real pelo mundo imaginário para, em seguida, apresentar o livro "Alice no País das Maravilhas", de Lewis Carroll, autor também de "Alice através do Espelho".

Cosson (ibid) enfatiza que a introdução da obra não deve se estender muito, pois a função desse momento é apenas permitir uma boa recepção da obra pelo aluno.

\section{5 - Leituras das obras}

Com o objetivo de aguçar o interesse do aluno para a leitura das duas obras selecionadas para esse trabalho e garantir a comparação das obras, no que tange aos diferentes contextos das histórias e ao comportamento das protagonistas, sugerimos iniciar esse passo com a leitura do livro "A Bolsa Amarela", já com o objetivo de discussão compartilhado. Trabalhamos com intervalos de leitura. Para isso, dividimos a obra em três grandes partes. Iniciamos a leitura de forma compartilhada, ou seja, o primeiro capítulo foi lido oralmente pelas professoras com a finalidade de aguçar a curiosidade do aluno para a continuidade da leitura. 
Concluída a leitura da primeira obra, adotamos o mesmo processo para a leitura da segunda, "Alice no País das Maravilhas", e, ao finalizarmos, os alunos assistiram aos vídeos com adaptações das obras: uma representação teatral do livro "A Bolsa Amarela" e uma versão em desenho animado de "Alice no País das Maravilhas", para que entrassem em contato direto com o maravilhoso, com o mágico, com o real. Assim, eles puderam entender melhor esses dois textos literários, além de terem a oportunidade de vivenciar novas sensações.

Esses intervalos de leitura são sugeridos por Cosson (2012) ao trabalhar sequências de leitura. $\mathrm{O}$ autor diz que "é durante as atividades do intervalo que o professor perceberá as dificuldades de leituras dos alunos [...] Na verdade, se bem direcionado, ele pode se constituir em um importante instrumento de aferição pedagógica do processo da leitura como um todo."

Para a próxima atividade, fomos com os alunos até o laboratório de informática para que eles vivenciassem parte da fantasia na realidade. Esse momento foi destinado a jogos da história de Alice no País das Maravilhas (visto que a própria história faz lembrar um jogo) e Segredos escondidos do País das Maravilhas, obra também já conhecida deles. Os jogos se configuram como uma espécie de livro digital, trazendo toda uma possibilidade de letramento digital através do suporte multimodal.

Devemos entender a leitura literária como possibilidade de acesso às diversas práticas sociais e à ligação com a realidade, evitando o ensino de literatura de forma estrutural, pois como diz Iser (1996) a grande lacuna dos estudos literários estruturalistas é dissociá-la das suas funções sociais.

Acreditamos que depois das atividades acima expostas, das intervenções das professoras e das experiências dos alunos com as leituras, já era o momento do trabalho de comparação das obras.

A seguir apresentamos os jogos e vídeos que foram explorados: 
Jogos - A obra vista pelos jogos

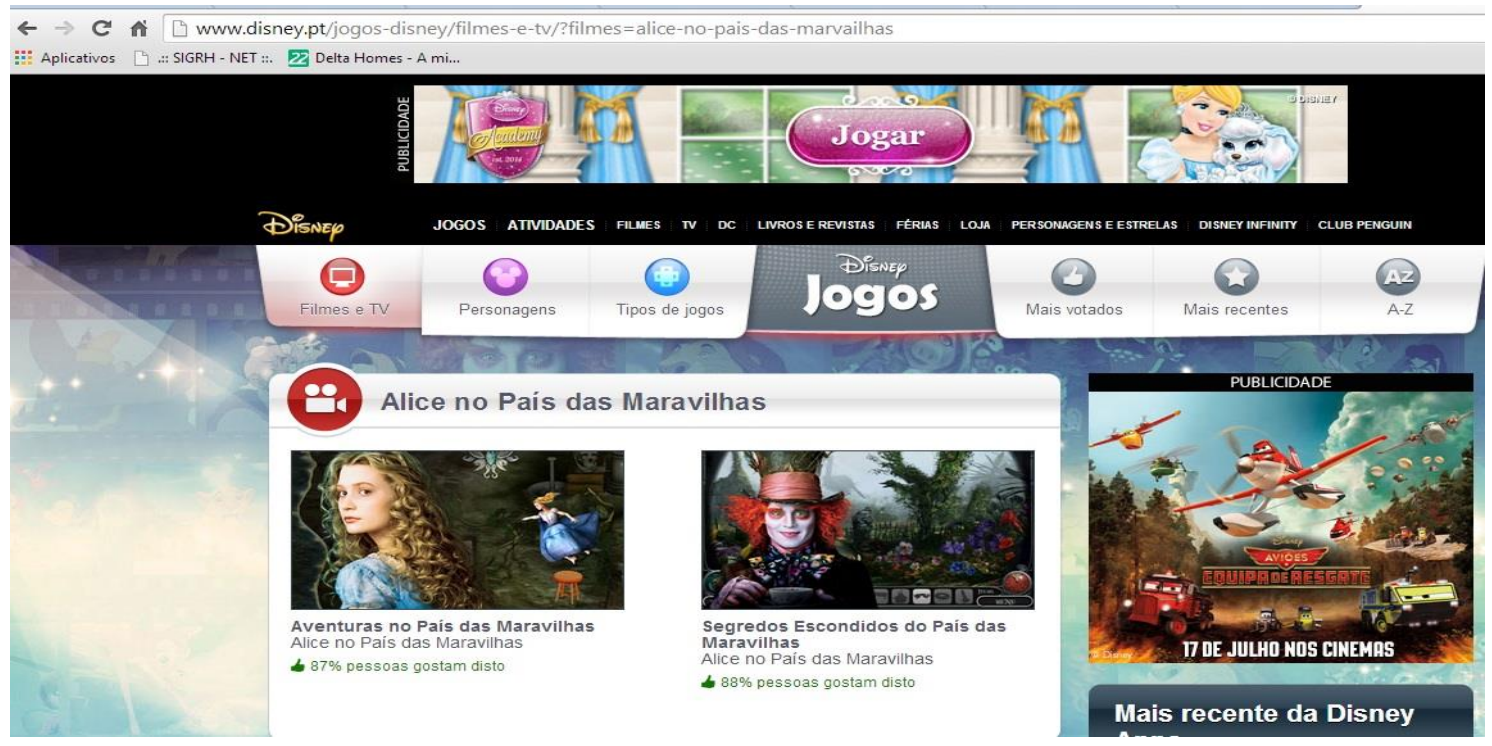

Fig. 2: Jogos Online. Fonte: <Disponível em http://www.disney.com.br/pt/jogos>.

Esse foi um momento de extremo envolvimento dos alunos. O domínio dos recursos digitais pelos alunos é surpreendente. Os que dominavam mais o uso de computadores, o acesso a sítios, ou a própria facilidade em lidar com os jogos, agiam como monitores, auxiliando os colegas. Fato é que os ambientes virtuais e as mídias de comunicação podem contribuir significativamente para a concretização de uma sociedade inclusiva.

Vídeo Bolsa Amarela - Adaptação da obra pelo teatro.

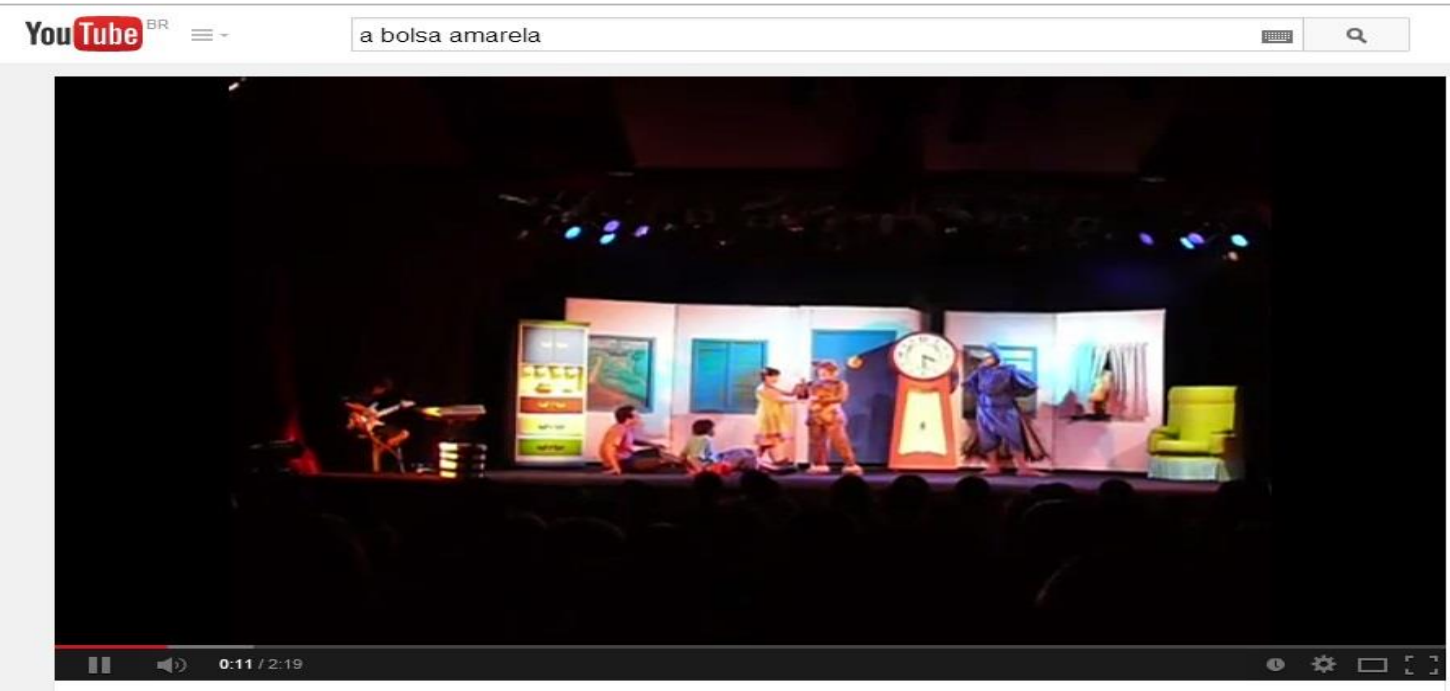

Renzo Reisch - A Casa da Madrinha, a menina da bolsa amarela.

Fig. 3 - A bolsa Amarela. Fonte: < Disponível em

https://www.youtube.com/watch?v=qvcyStmXf8E> 
Vídeo do livro Alice no País das Maravilhas - A obra vista pelo vídeo

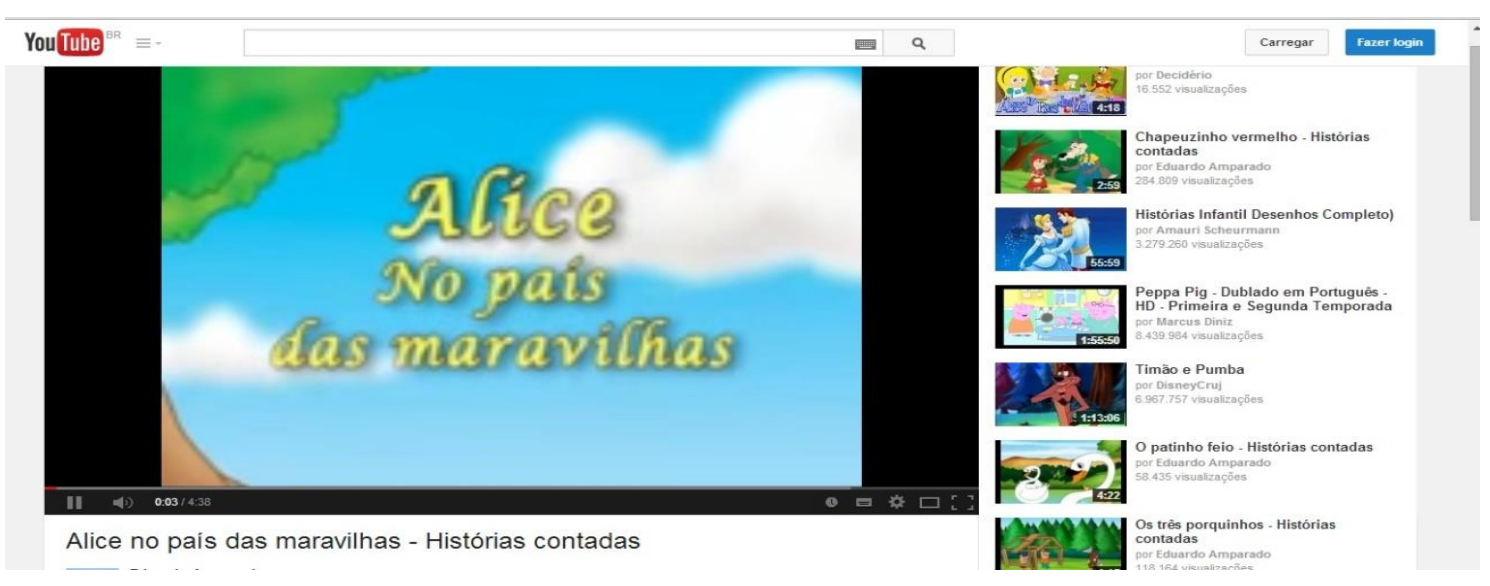

Fig. 4: Histórias contadas. Fonte: <Disponível em https://www.youtube.com/watch?v=YkkWu9tWa6Y> .

A interação dos alunos com esses ambientes virtuais de fantasia e realidade promove grandes transformações, pois pressupõe um espaço onde o aluno assume a responsabilidade da construção da própria aprendizagem.

Devemos aproveitar a grande oportunidade que se tem de observar os aprendizes, quando estão jogando, lendo, assistindo ou ouvindo uma história, pois certamente estão em pleno desenvolvimento, aprendendo a lidar com as suas próprias emoções e com o mundo em que vivem. Verificamos que trabalhar com a literatura dessa forma é assunto sério e deve ser usado para estimulação das diversas possibilidades de aprendizagem.

Ao acessar os jogos e assistir aos vídeos, foi possível notar a expressão de sentimentos, as ideias, a interação com os colegas, as iniciativas, a tomada de decisões. Ao comparar os dois vídeos, ou os dois livros, e os livros com os vídeos, os alunos puderam perceber nas obras, de forma mais efetiva, aspectos relacionados à arte, à estética e ao lúdico. Após todo acesso ao ambiente virtual, levantamos os seguintes questionamentos a fim de que os alunos os transferissem, posteriormente para o diário de leitura:

- Como você enfrenta os problemas no seu dia a dia? Para, analisa, procura saídas? Ou desiste e desanima? Percebeu como as personagens lidam com os desafios? 
- Quando um colega erra ou apresenta dificuldades, o que você faz? Oferece ajuda? Como as personagens ajudaram as pessoas (personagens das obras livros)? As soluções apresentadas nas obras diferem muito das soluções que você teria que tomar diante de um desafio parecido, na realidade?

Este momento de comparação, utilizando meios digitais, supõe a possibilidade de analisar novamente os fatos, os objetos, as situações, fomentando a organização das idéias. Os jogos e os vídeos, complementando a leitura das obras, servem tanto para diagnóstico, como para intervenção. Sabemos que o acesso à tecnologia, como complemento das atividades de leitura da obra física, valoriza não apenas o letramento literário através do verbal, mas os letramentos múltiplos, como o digital, e proporcionam ricos momentos de interação.

Após acesso à obra física, às atividades digitais e digitalizadas, às leituras, discutimos, em forma de debate, sobre as seguintes questões:

- A semelhança de comportamento de Alice e Raquel;

- As metáforas e as personificações contribuintes para a linguagem subjetiva precisa da literatura;

- A semelhança de desejos, de pensamentos e de comportamentos dos alunos com as protagonistas.

\section{6 - Interpretação: construindo um diário de leitura}

Mediante a vivência de leitura e as reflexões acerca da temática, julgamos pertinente o registro escrito das impressões a respeito das obras trabalhadas. Rouxel (2009, p.14) afirma que "devemos transformar a relação com o texto, reintroduzindo a subjetividade da leitura, humanizando-a, retomando-lhe 0 sentido."

Portanto, sapientes de que a prática do diário de leitura é uma forma ímpar de explorar o processo de leitura, propusemos a confecção de um pequeno diário em que ficassem registradas as práticas de leitura vivenciadas. Acreditamos que essa atividade leva os alunos a levantar questionamentos, a responder ou buscar 
respostas para esses questionamentos (assim como faziam as personagens Alice e Raquel).

Com certeza, esses registros levaram os alunos ao crescimento e à leitura de si mesmos, tendo em vista a semelhança das atitudes das personagens com as dos leitores adolescentes. Pedimos aos alunos que as reflexões anotadas nos diários envolvessem questões como comportamentos positivos das personagens que auxiliam no convívio com os adultos e como agir diante de opiniões que divergem das nossas. Sugerimos, ainda, que ilustrassem com passagens dos livros.

E, por último, solicitamos aos alunos, que trocassem os diários para que um conhecesse a experiência do outro de modo que que, ao dividir as suas experiências com outro, o aluno pudesse conhecer mais a si próprio, como o outro. Foi através das trocas que os alunos tiveram mais contato com o mundo e a linguagem polissêmica de "Alice no País das Maravilhas" e de "A Bolsa Amarela", adentrando no contexto do maravilhoso e do imaginário.

Sugerimos que, ao aplicar essa proposta, seja solicitado aos alunos que troquem seus diários para que um conheça a experiência do outro e, para que, ao dividir as suas experiências com o outro, o aluno possa de fato vivenciar situações de comunicação através de textos literários, ao conhecer as expectativas dos outros. Esse é o momento, também, de perguntamos se eles entenderam o porquê da terem ganhado uma bolsa amarela, (entregamos uma bolsa amarela confeccionada com TNT para os alunos como motivação de leitura da obra Bolsa Amarela). E que poderiam utilizá-la para guardar o diário de leitura.

\section{Considerações Finais}

Considerando que trabalhar com o livro literário é uma oportunidade de aproximar o leitor do texto, de envolvê-lo com o imaginário das obras, temos como critério de avaliação a interpretação do aluno sobre os textos literários. Não estamos, aqui, afirmando que todas as interpretações são possíveis, mas, sim, que com as diferentes interpretações abrimos espaços para negociações, discussões, para alcançarmos uma interpretação coletiva comum, uma comunidade de leitores. 
Participar desses momentos mágicos de leitura possibilita explorar diversas situações que fazem parte da vida, sob o prisma dos valores e emoções presentes no contexto escolar e na vida, possibilita também a crítica dos momentos difíceis, dando novos sentidos e conferindo oportunidade de sonhar, idealizar, imaginar.

Dentro do ambiente escolar, é possível refletir sobre as relações estabelecidas com os outros, com a realidade, com sonhos, com a cidadania, com a maravilhosa descoberta da aprendizagem. Para isso, as atividades que buscam o despertar do interesse do aluno e contribuem na formação de sujeitos críticos, utilizando a riqueza do mundo literário, são de extrema relevância.

As atividades pedagógicas de ensino de literatura realizadas devem propiciar, ao professor, informações sobre a turma, para que ele possa planejar suas aulas, partindo de obras mais simples para mais complexas. Nessa perspectiva, as atividades compreendidas nessa proposta contribuem para aprofundar os sentidos das duas obras, bem como permitir que o aluno e a turma tenham uma experiência de leitura.

Com isso, notamos que além de trazer contextos para prática, o professor deve criar condições para uma relação efetiva do aluno leitor com o texto, trabalhando com a história a partir de pontos de vista, trocando opiniões sobre ela, assumindo posições frente aos fatos narrados, defendendo atitudes de personagens. Como enfatiza Cosson (2012), "devemos ter sempre em mente que a leitura literária é um processo sem Ihe impor constrangimentos e empecilhos" (p.113).

Destarte, o trabalho com as obras "Alice no País das Maravilhas" e "A Bolsa Amarela", tal qual planejado, garante que os alunos desenvolvam um comportamento leitor autônomo.

\section{Referências bibliográficas}

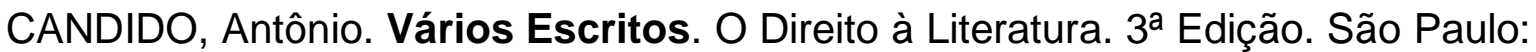
Duas Cidades, 1995.

CARROLL, Lewis. Alice no país das maravilhas. São Paulo: Summus, 1980.

COSSON, Rildo. Letramento Literário: Teoria e Prática, 2012. 
ISER, Wolfgang. $O$ ato da leitura: Uma teoria do Efeito Estético. Tradução Johannes Kretschmer. Editora 34, 1996.

NUNES, Lygia Bojunga. A bolsa amarela. Rio de Janeiro: Agir, 1998.

RAMPAZZO, Lino. Metodologia científica: para alunos dos cursos de graduação e pós-graduação. São Paulo: Loyola, 2002.

ROUXEL, Annie. Mutações epistemológicas e o ensino de literatura: $O$ advento do sujeito leitor. 2012. Disponível em <http://www.revistas.usp.br/criacaoecritica> Acesso em: 20 julho de 2014.

ROUXEL, Annie. Práticas de leitura: Quais rumos para favorecer a expressão do sujeito leitor? 2007. Tradução Neide Luzia de Rezende e Gabriela Rodella de Oliveira. < Disponível em www.scielo.br/pdf/cp/v42n145/15.pdf> Acesso em 27 de abril de 2015 
Artigo recebido em: 28 de abril de 2015

Artigo aprovado em: 11 de maio de 2015

\section{Sobre os autores:}

João Carlos Biella é doutor em Estudos Literários pela Universidade Estadual Paulista Júlio de Mesquita Filho (2004). Professor adjunto do lleel-UFU (MG).

Conceição Maria Alves De Araújo Guisardi é mestranda pelo PROFLETRAS Universidade Federal de Uberlândia. Possui experiência com ensino médio e ensino fundamental, aceleração da aprendizagem e educação integral.

Francisca Borges Barbosa é mestranda na Universidade Federal de UberlândiaUFU- PROFLETRAS - Mestrado Profissional em Letras. Possui experiência no ensino superior, nos cursos de Letras e Direito.

Caroline Costa Silva é mestranda pela Universidade Federal de Uberlândia, Seu trabalho é voltado para a área de Análise de Discurso Crítica, gêneros discursivos, estudo do texto literário/letramento e ensino de língua portuguesa. 